\title{
Typpitase huuhtoutumisen indikaattorina
}

\author{
Tapio Salo $^{1}$, Eila Turtola ${ }^{1}$ ja Juha Grönroos ${ }^{2}$ \\ ${ }^{1)}$ MTT, Ympäristöntutkimus, Maaperä ja ympäristö, 31600 Jokioinen, tapio.salo@mtt.fi \\ ${ }^{2)}$ SYKE, Ympäristöteknologia,00251 Helsinki,juha.gronroos@ymparisto.fi
}

\section{Johdanto}

OECD on arvioinut typpitaseen (OECD 2002) yhdeksi tärkeimmistä maatalouden ympäristöindikaattoreista. Typpitaseen avulla voidaan arvioida maatalouden ja ympäristön vuorovaikutusta sekä seurata maataloudessa tapahtuvia intensiteetin muutoksia. Typpitasetta arvioidessa on kuitenkin muistettava, että typpitase ei kerro todellista typen huuhtoutumaa vaan tarjoaa edullisen ja käytännöllisen työvälineen arvioida potentiaalista typen huuhtoutumaa (Parris 1998). Typpitasetta voidaankin käyttää huuhtoutuman arvioimisessa esimerkiksi elinkaarianalyysissä (Brentrup ym. 2001). Tämän tutkimuksen tavoitteena oli testata typpitaseen käyttökelpoisuutta kahdella huuhtoutumiskentällä mitatun typen huuhtoutumisen ennustamiseen.

\section{Aineisto ja menetelmät}

Aineistoina käytettiin MTT:n huuhtoutumiskenttiä Jokioisilla (1980-2001) ja Toholammella (19922000) (Turtola 1999). Jokioisten huuhtoutumiskentän maalaji on hiesusavi/aitosavi. Ensimmäisessä jaksossa 1980-1990 kentän viljelykierrossa oli nurmen- ja viljanviljelyä sekä avo- ja viherkesannointia. Salaojituksen parantamisen (Turtola ja Paajanen 1995) jälkeen (1994-2001) kentällä on verrattu kyntöä ja kultivointia viljanviljelyssä. Toholammen huuhtoutumiskentän maalaji on hieno hieta, ja kentällä on viljelty pääasiassa nurmea. Ensimmäisessä koesarjassa 1992-1996 testattiin lietelannan levitysajankohtia. Vuodesta 1997 alkaen osa kentästä on luonnonmukaisen tuotannon siirtymävaiheessa, ja kentällä on tutkittu mm. karjan- ja turkislannan lannoitusvaikutusta.

Huuhtoutumiskentillä tehdyistä kokeista laskettiin koeruuduittain ja vuosittain typpitase sekä typen huuhtoutuminen. Typpitaseeseen laskettiin lannoituksen ja mahdollisen typensidonnan tuottama typpi, josta vähennettiin korjatussa sadossa ja lannan ammoniakin haihtumisessa poistunut typpi. Huuhtoutumisvuosi jaettiin kevätvalunnan päättymisen mukaan. Huuhtoutunut typpi laskettiin kokonaistyppimäärityksen perusteella tai sen puuttuessa ammonium- ja nitraattitypen summana. Pinta- ja salaojavalunnassa huuhtoutunut typpi yhdistettiin. Toholammen kentällä viljeltyjen typensitojakasvien typenotto laskettiin käyttäen Tanskassa kehitettyjä yhtälöjä (Høgh-Jensen ym. 1998). Käytännössä tämä merkitsi, että biologinen typen sidonta oli $140 \%$ sadonkorjuussa poistuneesta typensitojakasvin typestä. Lannan ammoniakin haihtuminen laskettiin levityshetken lämpötilan, maan pinnan vedenläpäisykyvyn ja lannan pellon pinnalla oloajan mukaan (Horlacher ja Marschner 1990).

Typen huuhtoutumista selitettiin regressioanalyysillä vuosittaisen typpitaseen ja kokonaisvalunnan tai salaojavalunnan avulla. Toisessa analyysitavassa vuosittainen säävaihtelu poistettiin laskemalla analysoitavalle ajanjaksolle typpitaseen ja typen huuhtoutumisen keskiarvo. Samanlaista menetelmää ovat Norjassa käyttäneet Korsaeth ja Eltun (2000). Heidän tutkimuksessaan valunnan asemasta käytettiin sadantaa.

Ensimmäisissä tarkasteluissa jokaisen koeruudun vuosittainen typpitase ja typen huuhtoutuminen esitettiin samoissa kuvissa ja laskettiin mahdollisia selittäviä yhtälöjä. Koska vuosittaisilla taseilla ja typen vuosittaisella huuhtoutumalla ei näyttänyt olevan ruutukohtaisessa tarkastelussa yhteyttä (esim. Kuva 1), jaettiin kenttien aineistot ensiksi neljään osaan. Kotkanojan aineistoa tarkasteltiin ennen (1980-1990) ja jälkeen salaojituksen (1994-2001). Toholammen aineisto jaettiin lietelannan levityskokeeseen (1992-1996) ja lantakokeeseen (1997-2001). Koska vuosittainen typpitase ja valunta selittivät näissäkin neljässä aineistossa alle $50 \%$ huuhtoutumisesta, muodostettiin edelleen yhtenäisempiä viljelykiertoja ja käsittelyjä sisältäviä osia (Taulukko 1). 


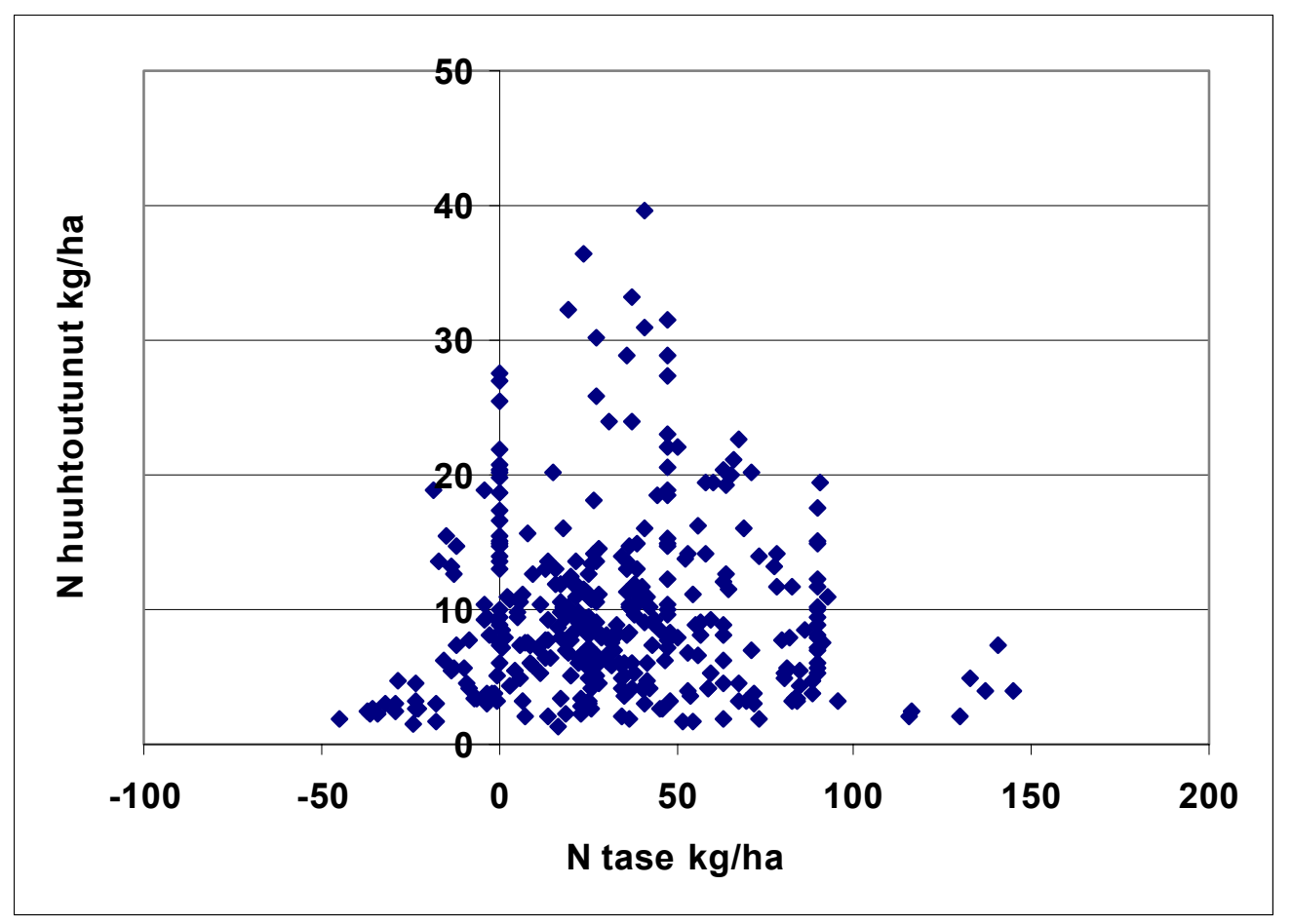

Kuva 1. Koeruutujen vuosittaisen typpitaseen ja typen huuhtoutuman yhteys Jokioisten Kotkanojan huuhtoutumiskentällä 1980-2001.

Taulukko 1. Huuhtoutumiskentiltä valitut koejaksot.

\begin{tabular}{lllr}
\hline Kenttä & Ajanjakso & Koekasvit & n/vuosi \\
\hline Kotkanoja & $1980-1984$ & nurmi & 8 \\
Kotkanoja & $1980-1986$ & vilja & 6 \\
Kotkanoja & $1980-1990$ & $\begin{array}{l}\text { nurmi tai vilja, jonka jälkeen avo- } \\
\text { kesanto }\end{array}$ & 8 \\
Kotkanoja & $1980-1990$ & $\begin{array}{l}\text { nurmi tai vilja, jonka jälkeen vi- } \\
\text { herkesanto }\end{array}$ & 8 \\
Kotkanoja & $1994-2001$ & vilja (kyntö) & 8 \\
Kotkanoja & $1994-2001$ & vilja (sänki tai kultivointi) & 8 \\
Toholampi & $1992-1996$ & nurmi (kevätlevitys pois) & 12 \\
Toholampi & $1992-1996$ & nurmi (syyslevitys pois) & 12 \\
Toholampi & $1992-1996$ & nurmi (kevät ja syyslevitys pois) & 8 \\
Toholampi & $1992-1996$ & nurmi (kevät ja talvilevitys pois) & 8 \\
Toholampi & $1992-1996$ & nurmi (syys- ja talvilevitys pois) & 8 \\
Toholampi & $1997-2000$ & nurmi (luonnonmukainen) & 12 \\
Toholampi & $1997-2000$ & nurmi (tavanomainen) & 12 \\
\hline
\end{tabular}

\section{Tulokset ja tulosten tarkastelu}

\section{Kotkanoja}

Typen vuosittainen huuhtoutuminen oli Jokioisten savimaalla $2-40 \mathrm{~kg} / \mathrm{ha}$ ja vuosittaiset typpitaseet 44-145 kg/ha. Viljanviljelyssä vuosittainen typpitase ja kokonaisvalunta selittivät enimmillään 55$63 \%$ vuosittaisesta typen huuhtoutumisesta. Parhaat selitysasteet $\left(\mathrm{R}^{2}=0,63\right)$ saatiin vuosien $1980-1986$ viljakierrosta (typen huuhtoutuminen $=-3,6+0,04 \times$ typpitase $+0,04 \times$ kokonaisvalunta) ja vuosien 1994-2001 sänkimuokkauksista (typen huuhtoutuminen $=-2.6+0.14 \mathrm{x}$ typpitase $+0.07 \mathrm{x}$ salaojavalunta). Keskiarvojen avulla typpitase selitti typen huuhtoumasta enimmillään $71 \%$. Tällöin viljelykierrossa, jossa viljaa tai nurmea seurasi avokesanto $1980-1989$, vaihteluvälillä $30-50 \mathrm{~kg} / \mathrm{ha}$ olleesta taseesta huuhtoutui keskimäärin $27 \%$. 


\section{Toholampi}

Toholammen hietamaalla vuosittainen huuhtoutuminen oli $2-104 \mathrm{~kg} / \mathrm{ha}$ ja vuosittaiset typpitaseet -63 - $417 \mathrm{~kg} / \mathrm{ha}$. Vuosien 1992-1996 lietelannan levityskokeissa saatiin vuosittaisella aineistolla vain alle $40 \%$ selitysasteita. Kun aineisto jaettiin käyttäen lannoittamatonta ja NPK-lannoitettua käsittelyä kunkin lietelannan levitysajankohdan kanssa, saatiin typpitaseiden keskiarvoille (Kuva 2) 69-98\% selitysasteet. Tällöin huuhtoutumisen osuus nousi 3:sta $25 \%$ :iin, kun siirryttiin vähiten huuhtoutumista tuottaneesta lietelannan kevätlevityksestä syys- ja talvilevitykseen.

Vuosien 1997-2001 koesarjassa typpitaseet olivat korkeita, mutta huuhtoutuminen alhainen. Vuosittaisessa aineistossa paras selitysaste oli vain $56 \%$ (typen huuhtoutuminen $=-1,2+0,02 \times$ typpitase $+0,09 \times$ salaojavalunta).

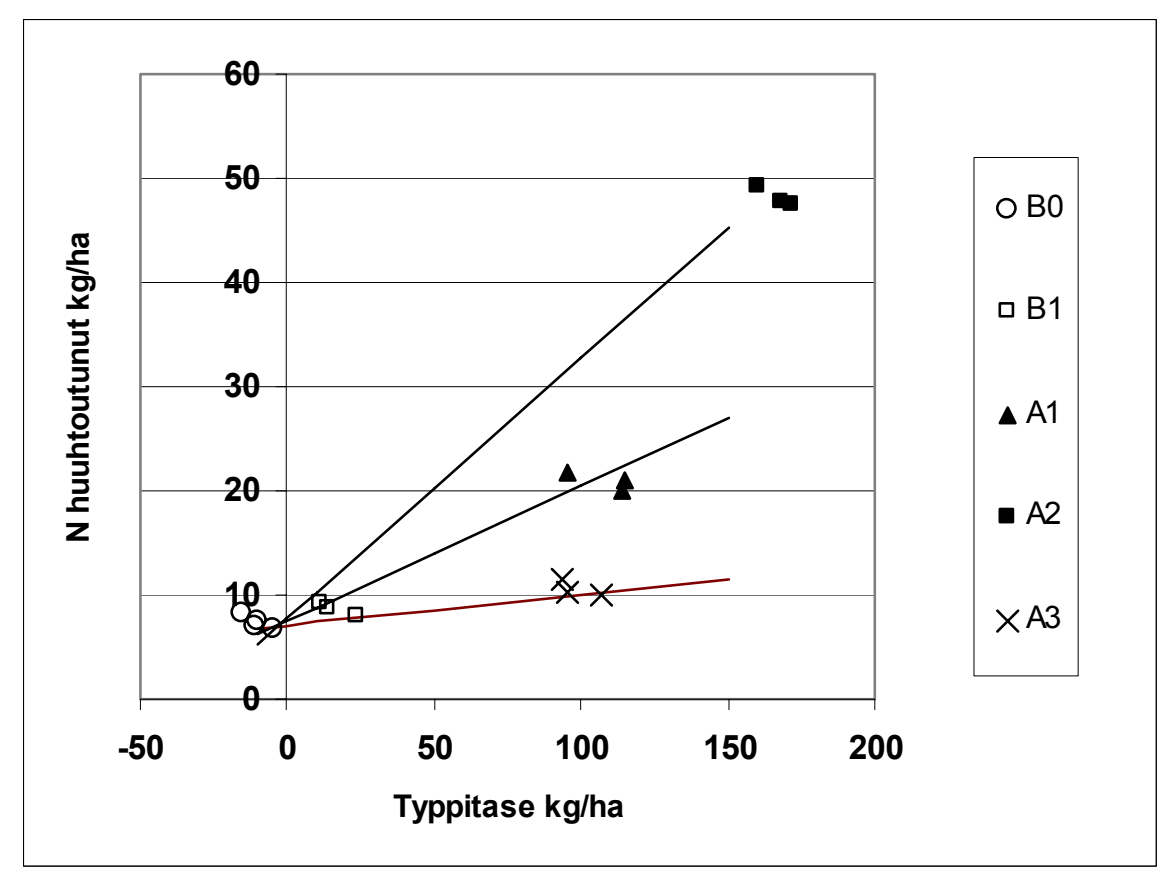

Kuva 2. Toholammen kentällä vuosilta 1992-1996 laskettujen vuosittaisten typpitaseiden ja typen huuhtoutumisen keskiarvot koeruuduittain. Viivat kuvaavat kunkin lietelannan levitysajankohdan vaikutusta huuhtoutumiseen. Käsittelyt: B0=lannoittamaton, B1=NPK-lannoitus, lietelannan levitys syksyllä $=\mathrm{A} 1$, talvella $=\mathrm{A} 2$ ja keväällä $=\mathrm{A} 3$.

\section{Johtopäätökset}

Vuosittainen typpitase ei selittänyt erityisen hyvin typen huuhtoutumista. Vuosittaisen typpitaseen ongelmana on maahan jäävä ja vasta seuraavina vuosina huuhtoutuva typpi (Mitchell ym. 2001). Samaten avokesannointi aiheutti korkean huuhtoutumisen taseen olleessa nolla. Parhaiten vuosittainen typpitase ennusti huuhtoutumista, kun viljelykierto ja käsittelyt olivat mahdollisimman samanlaisia. Samoin Norjassa tehdyssä valuma-aluetutkimuksessa saatiin parhaat selitysasteet, kun yhdistettiin maalajiltaan yhtenäiset valuma-alueet ja samanlaiset vuosittaiset säät (Bechmann ym. 1998). Korsaeth ja Eltun (2000) havaitsivat omasssa tutkimuksessaan sadannan olevan typpitasetta merkittävämpi vuosittaisen huuhtoutuman selittäjä. Useamman vuoden keskiarvona laskettava typpitase näyttääkin olevan käyttökelpoisempi ennustettaessa huuhtoutumista vaihtelevassa viljelykierrossa. Korsaeth ja Eltun (2000) saivat typpitaseesta huuhtoutuvaksi osuudeksi viljanviljelyssä $15 \%$ ja nurmenviljelyssä $10 \%$.

Epäedulliset viljelytekniikat, kuten nykyisin kielletty lietelannan levitys talvella tai avokesanto, liittyivät korkeisiin typen huuhtoutumisiin enemmän kuin korkeat typpitaseet. Typpitaseen todettiinkin selittävän varsin hyvin typen huuhtoutumista, kun viljelytekniikat sisälsivät huuhtoutumista lisääviä menetelmiä kuten avokesantoa ja lietelannan talvilevitystä.

\section{Kirjallisuus}


Bechmann, M., Eggestad, H.O. \& Vagstad, N. 1998. Nitrogen balances and runoff in four agricultural catchments in southeastern Norway. Environmental Pollution 102: 493-499.

Brentrup, F., Küsters, J., Kuhlmann, H. \& Lammel, J. 2001. Application of the Life Cycle Assessment methodology to agricultural production: an example of sugar beet production with different forms of nitrogen fertilisers. European Journal of Agronomy 14:221-233.

Horlacher, D. \& Marschner, H. 1990. Schätzrahmen zur Beurteilung von Ammoniakverlusten nach Ausbringung von Rinderflüssigmist. Zeitung für Pflanzenernährung und Bodenkunde 153: 107-115.

Hogh-Jensen, H., Loges, R., Jensen, E.S., Jørgensen, F.V. \& Vinther, F.P. 1998. Empiriskmodel til kvantificering af symbiotisk kvælstoffiksering i bælgplanterna. In. Kvælstofudvaskning og -balancer I konventionelle og økologiske produktionssytemer. Eds. Steen Kristensen, E. \& Olesen, J.E. Forskningscenter for Økologisk Jordbruk. 69-86.

Korsaeth, A. \& Eltun, R. 2000. Nitrogen mass balances in conventional, integrated and ecological cropping systems and the relationship between balance calculations and nitrogen runoff in a 8-year field experiment in Norway. Agriculture, Ecosystems and Environment: 79: 199-214.

Mitchell, R., Webb, J. \& Harrison R. 2001. Crop residues can affect N leaching over at least two winters. European Journal of Agronomy 15: 17-29.

OECD. 2002. Gross nitrogen balances. Handbook. The 2nd draft 30 September 2002. http://webdomino1.oecd.org/comnet/agr/nutrient.nsf

Parris, K. 1998. Agricultural nutrient balances as agri-environmental indicators: an OECD perspective. Environmental Pollution 102: 219-225.

Turtola, E. 1999. Phosphorus in surface runoff and drainage water affected by cultivation practices. Academic Dissertation. University of Helsinki. 47 p.

Turtola, E. \& Paajanen, A. 1995. Influence of improved subsurface drainage on phosphorus losses and nitrogen runoff from a heavy clay soil. Agricultural Water Management 28: 295-310. 